Has any one, in the discussion of Mallet's hypothesis, thought of bringing its probability to such a test as the volatilisation of the hydrocarbons of coal-beds in a highly plicated region like Belgium?

It is a remarkable fact, and one which seems to me inconsistent with the mechanical theory of earth-heat, that of two extensive regions, Belgium and Eastern Pennsylvania, equally and excessively disturbed by complications, all the coal-beds of the one are anthracite, and all those of the other are bituminous.

Again, of two regions equally undisturbed, Western Pennsylvania and Arkansas, the horizontal coal-beds of the one are bituminous and of the other anthracite.

Surely, if movements of stratum on stratum produce all the needful heat, no plicated coal-beds should escape being converted to antbracite; and I should much like to hear from English geologists how this argument is to be met. My own explanation of the origin of anthracite is not worth much, but it is the best I know. I refer such origin to three causes acting in conjunc. tion-(I) Heat due to superposed (now wholly or partially re. moved) Permian and later formations; (2) Greater proportion of sands in the anthracite and of clays in the bituminous coalmeasures; and (3) Plication and fracture, permitting the exit of volatilised hydrocarbons into the atmosphere.

American Philosophical Society, Philadelphia, May 22

\section{Evolution Old and New}

Mr. A. R. WALlace writes, in Nature, vol. xx. p. I43, that, according to the theory which I support, Australian (and more especially Queensland) sheep should show a tendency to grow a scantier and thinner fleece than their English ancestors. "If Mr. Butler," he continues, "could adduce on good authority such a fact as this, he would have some evidence in his favour, instead of which he can only make suppositions."

I never was in Australia, but had some years' experience of sheep-farming in New Zealand. It was generally believed, in my time, that fleeces soon became short and hairy in Queensland, and even in the more northern part of New South Wales. You must, however, have many readers who could tell us what the facts are. May I hope that you will kindly insert this, so as to get the matter settled by eliciting information from a competent authority? I am speaking, of course, of sheep that are left to the effect of the climate, without being frequently crossed with rams from colder countries. Do the fleeces of such sheep deteriorate in Queensland?

S. BUTLER

June 12

\section{The River Elbe}

IN NATURE, vol. xiv. p. 498 , some particulars are given of measurements made in $187 \mathrm{I}$ and 1872 of the water flowing past in the Elbe at the boundary between Saxony and Bohemia. The river basin in Bohemia above this point is stated at 880 square miles, which is evidently wrong, as the annual discharge of 6 , I $79,000,000$ cubic metres ( $218,223,743,000$ cubic feet) would give a depth of $107^{-64}$ inches run off the ground. Measuring roughly on the map, the area of Bohemia-which, apparently, all drains into the Elbe-is 20,000 English square miles. If, on the other hand, the measurements of the river water and the solids in solution and suspension are correctly given, and the river basin is 20,000 square miles, the rainfall must have been exceptionally low at the time the measurements were taken, as the figures represent only about half that of the mean annual flow off the ground in the Danube basin, which is $9^{\circ} 06$ inches. Perhaps the writer of the notice will be able to find out how these discrepancies occur. I may add that, taking the figures as given in NATURE, 607 tons per square mile per annum are removed in solution in the Elbe water. From a district com. posed mostly of silurian rocks, this is manifestly absurd. According to my calculations, ${ }^{1} 72^{\prime} 7$ tons per square mile are annually removed in solution in the Danuber square

Blindellsands, June i 7

\section{T. Mellard ReAde}

\section{Electric Light}

IN NATURE, vol. xx. p. IIO, an account is given of Sir William Thomson's evidence on the electric light. It is stated "that one horse-power had produced $\mathbf{I}, 200$ candles of actual r "Geological Time," Proceedings of Liverpocl Geological Society, Session
$\times 876-7$. visible electric light, whereas one horse-power of energy would only produce 12-candle gas-light." In the report of Sir J. W. Bazalgette and Mr. Keates to the Board of Works, which is probably the best report we have yet had on the subject, as to the actual cost of the electric light on the Thames Embankment, it is stated that the cost of the electric light was $5{ }^{\circ} 75^{d}$. per hour, whereas the cost of the gas required to produce a light equal to the electric light as regards illuminating power, in an opal globe, was $2.00 d$, and in a frosted globe $3.50 d$. per hour. Would any of your numerous readers be kind enough to give me some idea of the qualifications to be appended to the above statements, which will reduce the long odds calculated by Thomson of $I 00$ to $I$ in favour of the electric light, to the odds of 2 to $I$ against it as found in actual practice? In conclusion may I venture humbly to suggest that such conflicting statements as the above, if unexplained, are apt to bring the dicta of scientific men into disrepute with the thinking portion of the general pablic.

F. J. M. P.

\section{The Climbing Perch}

THE aquarium of the Zoological Society's Gardens in Regent's Park has lately received a contribution of five specimens of the "Climbing Perch" (Anabas scandens). They were very kindly obtained for me by my friend, Mr. A. Ferguson, of Colombo, Ceylon, and were brought home in excellent condition by my brother, Mr. A. F. Dobson. Mr. Ferguson (who is so well known in Ceylon as a naturalist of great experience) kept the fish for some months in an aquarium, and trained them to take chopped meat from the hand, so that they were in the best possible condition for their long journey.

The first specimens of this fish which arrived alive in Europe were sent by me from Calcutta in 1872 to the Royal Zoological Gardens in the Phonix Park in Dublin, where they lived for a considerable time.

I have described (P. Z. S., I874), in my paper "On the Respiration of Indian Fresh-water Fishes" the manner in which Anabas scandens takes in, and rejects again, the atmospheric air, and on a visit to the aquarium in the Gardens the peculiar conduct of these fishes when respiring may be witnessed by any one.

Mr. Ferguson informs me that he has specimens of some species of Ophiocephali and the remarkable Arizus bakeri, which carries its young in its mouth, in training, and I hope soon to have an opportunity of having them safely carried to England.

Netley, June 14

G. E. DOBSON

\section{Oxygenated Rain}

ON Thursday, June 12, at half-past eleven in the morning, $x$ remarkable shower of rain fell over. London, which might almost be described as " effervescing ;" the drops whilst falling appeared to be colourless and perfectly transparent, but on striking against any solid surface they became milky, and on close examination it was evident that this cloudy appearance was caused by a number of very minute air-bubbles, which rapidly increased in size, and then burst. From the bleaching power which this rain. appeared to have, I am led to believe that there was nascent oxygen in the gas thus evolved. Those who traverse the streets of London in the early morning may now and then observe the red colour of all bright iron-work in the pavement, such as coalplates, \&c., due to the oxidising influence of a thunder-shower in the night; this effect does not follow every thunder-shower, but seems to indicate a peculiar atmospheric condition. Have any memoranda on this subject been recorded?

EDWARD SOLLY

\section{WILLIAM FROUDE I}

AST week we called attention to Mr. Froude's discoveries of those laws of motion of floating bodies, upon which the behaviour and safety of a ship passively floating among sea waves depends. We now purpose giving a brief outline of his researches in another branch of hydrodynamics by which he arrived at a true appreciation of the nature and amount of the resistance opposed by water to the passage of a body like a ship through it. In connection with the resistance of ships, the subject of marine propulsion, which Mr. Froude bas also done much 
to elucidate and bring within the grasp of scientific treatment, will naturally find a place.

The resistance of ships and the speeds that could be relied upon in practice by the application of a given amount of force has always been a fruitful source of trouble to naval architects and engineers. The various formulæ that have been used for calculating the speed of ships, and which were based upon what were supposed to be the true laws of resistance, have always been uncertain and unreliable in their application. Mr. Froude has shown that this is because the approved formulæ "were not only wrong in detail, but that the supposed cause of resistance, with which alone they professed to be dealing, was in reality no cause at all; and that the real cause of resistance, whatever it might be, was entirely left out."

This supposed cause of resistance, which "was in reality no cause at all," was alleged to be due to the inertia of water, and the necessity for pushing those particles out of the way which offer an obstruction to the progress of a ship through the fluid. Thus it seems that there must be an excess of pressure upon the fore part of a ship when she is excavating or pushing water out of her way; and a diminution of pressure or partial vacuum on the after part when she is travelling away from the particles which press against her. There would therefore be a total resistance caused by excess of pressure forward and deficiency of pressure aft. As this resistance would depend upon the volume of water that would have to be pushed out of the ship's way; it appeared obvious that it must be measured by the area of the ship's cross section.

These considerations were expressed in the following formulæ, which have been those chiefly used by shipbuilders till the last few years, and have been preferred by the Admiralty to any other down to the time when they placed the determination of the speeds of ships in Mr. Froude's hands. The formulæ are--

$$
V^{3}=\frac{C_{1} A}{P} \text { or }=\frac{C_{2} D^{3}}{P} \text {. }
$$

when $V=$ the speed of the ship, $A=$ the area of the greatest immersed cross-section, or "the area of the ship's way," $D=$ the ship's displacement, $P=$ a measure of the propulsive force, which stands for the indicated horsepower of the engines, and $C_{x}$ and $C_{2}$ are constants obtained from the observed performances of other ships. These are only formula of comparison between different ships, and were always regarded as being strictly applicable only to the comparison of ships of similar form. They are obviously based upon the assumption that the resistance is as the square of the speed and the area of the vessel's way, or of the canal she may be supposed to cut through the water in going from place to place. This is strictly the assumption in the first formula, which includes the exact area of the immersed cross-section of the vessel; but in the second formula, though the character of the assumption is the same, the area is corrected to represent the supposed equivalent cross-section for variations of displacement.

These formulæ gave fairly accurate results when applied to vessels of good form which were similar to those from which the constants were derived, and when the speeds were low. It was known, however, that the speeds of vessels of exceptional form and dimensions could not be thus calculated, and that in all ships the resistance increased at a faster rate than the square of the speed beyond certain limits, which limits were different in different ships. The development of the true laws of fluid motion, or the doctrine of stream-lines, by Prof. Stokes, Prof. Rankine, Sir William Thomson, and others enabled the real causes of a ship's resistance to be ascertained. It was then seen to be quite wrong to suppose that the work done in propelling a ship is in any degree analogous to excavating a canal, and spreading the water she successively displaces over the surface.
The stream-line theory showed that the reactions which the inertia of the fluid would cause against the surface of a ship moving through it arranged themselves quite differently to what had formerly been supposed, and that such methods of estimating their total effect--which was supposed to constitute the resistance-as we have referred to were fundamentally wrong. Indeed it shows that there is nothing in nature to correspond with the old idea of head resistance, because, according to the stream-line theory, a submerged body such as a fish, or a torpedo, once put in motion in a frictionless fluid would continue to travel with an uniform speed, and experience no resistance. Certain particles of fluid would have to be set in motion to enable such a body to pass them, but this would be done in such a way as to cause no resistance in the direction of motion. The backward forces acting upon the body on some parts of its surface would be balanced by the forward forces acting upon other parts, and the inertia of the fluid would propel it forward at some points with an equal force to that opposed in resistance at other points.

Mr. Froude showed most clearly and conclusively how this paradoxical result came about in his presidential address to the mechanical section of the British Association delivered at Bristol in August, $1875,{ }^{1}$ and also in a lecture delivered at the Royal Institution on May 12, 1876. He proves that in a perfect or frictionless fluid there is no power by which any endways resistance can be caused to the passage of a submerged body moving uniformly through it. Substituting for the submerged body moving through a stationary ocean of fluid the plainly equivalent conception of a stationary submerged body surrounded by a moving ocean of fluid, Mr. Froude points out that at a sufficient distance ahead of the body the ocean is flowing steadily on, in what may be imagined to be a collection of streams of any size and cross-section we please. All these streams must have the same direction, velocity of flow, and pressure. In order to get past the body these streams must alter their direction and velocity, settling themselves into courses which will be determined by the various reactions they exert upon each other and upon the surface of the body-" "yet ultimately and through the reverse operation of corresponding forces, they settle themselves into their original direction and original velocity. Now the sole cause of the original departure of each and all of these streams from, and of their ultimate return to, their original direction and velocity, is the submerged stationary body; consequently the body must receive the sum total of the forces necessary to thus affect the streams. Conversely this sum total of force is the only force which the passage of the fluid is capable of administering to the body. But we know that to cause a single stream, and therefore also to cause any combination or system of streams to follow any courses changing at various points both in direction and velocity, requires the application of forces the sum total of which in a longitudinal direction is nil, provided that the end of each stream has the same direction and velocity as the beginning. Therefore the sum total of the forces (in other words, the only force) brought to bear upon the body by the motion of the fluid in the direction of its flow is nil."

A frictionless fluid would, therefore, offer no resistance to a submerged body moving through it. Mr. Froude next introduced the consideration of friction, which brings two causes of resistance into play. First, there is the friction proper which is due to the drag of the particles of water upon the surface of a body as it moves through it, and which is governed in amount by the area of the surface, and also by its nature, whether smooth or otherwise ; and secondly, there is the defect of pressure at the rear end of the body caused by the stream, line motions being somewhat impeded by friction between the

${ }^{r}$ Published in Nature of November 18 , December 2, r6, and 30,1875 . 
particles. This is very obvious in blunt-ended bodies where the stream-lines, instead of closing in round the rear end and exerting their due pressure in the direction of motion, force themselves into eddies and whirls. Mr. Froude calls this element of resistance "eddy-making resistance." It is imperceptible in ships of fairly easy shape, but is of large amounts in ships with very full sterns. He shows that a submerged body of good easy shape would practically experience no resistance except that due to surface friction, and the amount of resistance would be practically the same as that of a thin plane moving edgeways, which has the same area of wetted surface.

Mr. Froude next shows that when we come to the case of a ship or a body travelling at the surface, a new cause of resistance is introduced, due to the system of surfacewaves which is generated. The variation of pressure in the stream-lines formed at the sides of a ship relieves itself at the surface by raising or lowering the level, and thus a bow and stern wave with a depression amidships are formed and carried along as the ship progresses. These waves once made, however, require little force for their maintenance, so long as they are not swollen to abnormal dimensions by the increased wave-making tendency a ship possesses at high speeds. Other systems of waves are also generated and driven off from the ship in various directions by features of form that interfere with the natural courses of the stream-lines. There are, therefore, three great causes of resistance to a ship: I, surface friction; 2 , eddy making; and 3 , wave genesis. Mr. Froude shows that the first, viz., surface friction, practically agrees with the resistance experienced by a plane of the same wetted surface drawn longitudinally through the water at high speeds, and that the eddymaking resistance is practically nothing in well-formed ships having fine ends; but that the wave-making resistance is so indeterminate in its character as to be incapable at present of direct calculation.

Mr. Froude estimated the total amount of a ship's resistance by means of careful experiments with a model made to her exact form. The method of doing this with accuracy is one of Mr. Froude's greatest and most useful discoveries. Model experiments of this nature that had previously been made were so misleading that it was generally believed to be impossible to infer the resistance of a ship from that of a small scale model. Mr. Froude saw, however, that all three elements of resistance followed the same laws in similar bodies, whatever the differences of size might be, and that all that was required to make experiments with models reliable was to discover the true scale of comparison. This scale, or law of comparison, he discovered, and stated as follows:-"If the ship be $D$ times the 'dimension' (as it is termed) of the model, and if at the speeds $V_{1}, V_{2}, V_{3} \ldots$ the measured resistances of the model are $R_{1}, R_{2}, R_{3} \ldots$, then for speeds $\sqrt{D} V_{1}, \sqrt{D} V_{2}, \sqrt{D} \cdot V_{3} \ldots$ of the ship the resistances will be $D^{3} R_{1}, D^{3} R_{2}, D^{3} R_{3} \ldots$ To the speeds of model and ship thus related it is convenient to apply the term "corresponding speeds" ; the special feature of this "correspondence" being the fact that at such speeds precisely similar wave systems are generated by ship and model.

Mr. Froude tried in 1867 a large number of resistance experiments with models of various forms and dimensions, by towing them from the ends of ro-foot scale beams, connected with self-recording dynamometric apparatus, and mounted on booms projecting sideways from the bow of a steam-launch. Some of the results were in glaring contravention to the ordinary principles current at the time, and Mr. Froude invited Mr. E. J. Reed, C.B., M.P., who was then Chief Constructor of the Navy, to witness the experiments. Mr. Reed saw the necessity for fresh investigation, and by his recomnendation a further series of experiments was sanctioned by the Admiralty.
These experiments were brought into further prominence by the action which was taken upon a report of a committee of the British Association in 1869, upon the stability, propulsion, and sea-going qualities of ships. On the recommendation of this committee an application was made to the Government for carrying out experiments upon resistance with actual ships of considerable size. Mr. Froude, who was a member of the committee, dissented from this report on the ground that the various elements of resistance and the laws of their operation "could be discovered with far greater facility and completeness by small-scale than by full-size experiments." The Admiralty requested Mr. Froude to conduct an extensive series of experiments with models; this he undertook and continued up to the time of his death with the greatest skill and success. The results thus obtained furnished data for determining the resistance of ships of various forms and dimensions to a considerable degree of exactness, and also showed what circumstances were favourable to speed and what were not.

This subject had an important bearing upon some of the inquiries instituted by the Committee on Designs for Ships of War, in $187 \mathrm{I}$, and they requested the Admiralty to determine experimentally the actual resistance of a full. sized ship. The Admiralty accordingly ordered the requisite experiments to be made upon H.M.S. Greyhound, a vessel of about I, I50 tons displacement. The experiments were made under Mr. Froude's superintendence. The Greyhound was towed by H.M.S. Active, and the resistance at various speeds recorded by means of a delicate dynamometric apparatus. She was towed from the end of a long outrigged boom, so as to be clear of the wake of disturbance, and every possible precaution was adopted to eliminate all the various sources of error. The experiments verified to a remarkable degree the law of comparison propounded by Mr. Froude as governing the relation between ships and their models, and perfectly justified the reliance he had placed upon his method of investigating the effects of variation of form by trials with varied models, a method which, as Mr. Froude afterwards remarked, "if trustworthy, is equally serviceable for testing abstract formula, or for feeling the way towards perfection by a strictly inductive process."

The value of Mr. Froude's method of calculating the speeds of ships from those of their models, became so obvious, that the Admiralty discarded their old methods, and referred their designs to Mr. Froude for his estimate of their speeds. Besides the elaborate series of experiments which Mr. Froude has had in course of procedure at his experimental tank at Torquay for determining the best form and proportion for various classes of ships, designed for various speeds, most of the new Admiralty designs have been experimented upon and moditied forms suggested where improvement could be made. The results of his work, and especially of the recent trials of H.M.S. Iris, whose lines were determined by Mr. Froude for the high speed of $17 \frac{1}{2}$ knots-have borne striking testimony to the correctness of his work.

Mr. Froude has, however, done much more than show how to calculate with accuracy the speed of a ship from that of her model. He has shown how the various elements of resistance act upon a ship at given speeds, and the laws upon which they depend. In well-formed steamers the resistance at low speeds consists almost entirely of surface-friction. This was the case in H.M.S. Greyhound at a speed of eight knots. If a curve of total resistance be made from experiments with a ship or resistance be made from experiments with a shipe also placed, and a curve of fine, they will be found almost placed on the same baseds. The resistance due to the formation of eddies is so small in well formed ships as to be hardly appreciable. When a ship of tolerably fine lines is moving at a moderate speed, the whole resistance, therefore, consists of surface-friction. As the speed 
is increased, the curve of total resistance ascends more or less above the curve of frictional resistance, and in some cases teparts very largely from it. The rate of departure as the speed increases differs largely in different ships, and in vessels of the same section, but of different lengths. Mr. Froude conducted a series of experiments upon models of the same cross section and form of ends, but with the length successively increased by lengths of parallel middle body. These models corresponded to ships of lengths varying from I 60 feet to 480 feet in total length. At the lower speeds, up to about eleven knots, the resistance increased by about equal increments with equal increments of length of the ship, but at higher speeds this harmony disappeared. At thirteen knots the 200-feet ship makes considerably more resistance than the 240 -feet ship, and at $14 \frac{1}{2}$ knots the 200 -feet ship makes almost as much resistance as a $360-$ feet ship of 2,275 tons more displacement. Similar anomalies appear in the comparison between other ships. These were shown by Mr. Froude to be due to the infuence of wave-making resistance, and to depend upon the positions occupied with reference to the stern of the ship by the waves generated by the bow. The practical point involved is that a ship may sometimes be lengthened considerably without any loss of speed for the same application of power; whereas if the conditions favourable to this are not complied with, she may, on the other hand, require a disproportionate increase of power to keep up her speed. Mr. Froude has shown how the most favourable conditions can be realised in this respect.

These investigations into the resistance experienced by ships at different speeds have thrown great light upon that long-disputed problem in naval architecture, "the form of least resistance," and has gone far to enable shipbuilders to arrive at the best form and proportions for the speed required, which is compatible with other requirements. Economically such a discovery is of great value in enabling more work to be done in steamship propulsion for a given engine-power and expenditure of fuel.

Mr. Froude's dynamometric experiments upon the resistance of the Greyhound, and some results of the steam trial performances of other ships, showed him that the actual resistance of a ship was much less than had been generally supposed. At eight knots speed the pull upon the tow-rope of the Greyhound-a ship of I, I5O tons displacement-was only $2 \frac{1}{2}$ tons, and at ten knots 43 tons. This was so very much below the thrust the screw was supposed to exert when driving the ship at those speeds, that Mr. Froude set to work to investigate the relation between the indicated horse-power of marine engines as represented by the work done by the steam in the cylinders, and the power that is usefully employed in propelling the ship. He found, as the result of many experiments, that in ordinary ships at full speed the former is 277 times the latter, or that the effective horse-power, as given out by the thrust of the screw, is only $37 \frac{1}{2}$ per cent. of the power indicated in the cylinders.

Mr. Froude decomposed the indicated horse-power of the engine into its constituent parts, and approximately quantified each element as follows :-

I. The useful thrust or ship's true resistance $=$ E.H.P. or the effective horse-power.

2. The augmentation of the ship's resistance by the induced negative pressure under the stern consequent on the thrust of the screw. Mr. Froude often called attention to this cause of resistance, and showed that it might be greatly reduced by placing the screw a short distance abaft its usual position. He ascertained by experiment that with ships of ordinary form the resistance is increased on account of the action of the screw by about 40 or 50 per cent. of her nett resistance. The power required for this therefore $=0^{\circ} 4$ E.H.P.
3. The friction of the screw blades in passing through the water, which was found to be $=O$ I E.H.P.

4. The constant friction due to dead weight and the tightness of the moving parts. This is at all speeds about one-seventh of the total load of the engines when working at full speed and pressure. It is therefore $=0.143 \mathrm{I}$. H.P., I.H.P. being the total indicated horse-power.

5. Friction due to working load of engine. This is also $=0.143$ I.H.P.

6. Air-pump resistance. This is approximately equal to 0.075 I.H.P.

Summing up these several elements it will be found that the effective horse-power at full speed is little more than $37 \frac{1}{2}$ per cent. of the indicated horse-power.

This analysis of the manner in which the power of the engines is employed is very valuable in indicating the manner in which loss of power may be treated in detail, and also in furnishing a reliable means of comparison between the efficiency of different engines. It will take time to come into general use, but cannot fail to do so as it becomes understood and appreciated. Already some of our most intelligent shipbuilders, such as Mr. Denny of Dumbarton, and Mr. Inglis of Glasgow, have applied Mr. Froude's theories to practice, and are working upon the improved methods he has laid down both for increasing the effect in the propulsive power of the engines, and in diminishing a ship's nett resistance.

The general adoption of these theories will be a great boon to science, as well as a practical benefit, in point of economy to the ship-builder and ship-owner. Science will benefit by having the performances of ships recorded in such a manner as will be available for correcting the present theories, and throwing light upon such laws of hydrodynamics as are yet undiscovered or but imperfectly understood.

One great difficulty in making any scientific use of steamship performances has arisen from the absence of any method of determining the power delivered to the screw. All that was ever ascertained was the power indicated in the cylinders, and, as we have seen, this was found to be enormously in excess of the effective power employed in propulsion. As the problems of resistance and propulsion can only be accurately treated by dealing with the thrust exerted by the screw, it became desirable to have some means of measuring this in actual ships. Mr. Froude, who had frequently pointed this out, was asked by the Admiralty to devise a dynamometer that would measure the power delivered at the end of the screw shaft in large marine engines. The problem was a most difficult one, but Mr. Froude solved it in a most complete and admirable manner. He described the instrument he had invented in a paper read before the Institution of Mechanical Engineers in July, 1877 , and a description of it is given in NATURE, August 2, I877. It fulfils all the conditions of giving a true indication of the power, being simple, compact, and easy of application. A machine for dealing with an engine of 2,000 I.H.P. is all included in the circumference of a circle of three feet radius, and as its power increases as the fifth power of its linear dimensions, it can be applied to any size of engine without becoming unduly large.

We have glanced hastily over some of Mr. Froude's achievements in science, but it is impossible within the limits at our disposal to do more than glance at them, or even to refer to many. He was a scientific worker of the best and rarest type, and was constantly employed in perfecting the details of his theories or striking out new lines of thought. He was a master of the delicate art of experimental and theoretical investigation, and a study of his work would show many perfect examples of the manner in which, by induction, a knowledge of the causes of phenomena may be arrived at. Being an excellent mechanic, and a most conscientious and ingenious experimentalist, Mr. Froude put all his theories and 
hypotheses to the most crucial and varied practical tests, and conclusively proved their truth, or determined the limits of error involved by them. He had the power of arranging almost intuitively simple experiments for qualitatively testing the value of an idea, and his mathematical knowledge and power of close and accurate reasoning enabled him to work out the quantitative results of a difficult problem with great facility. His experimental tank at Torquay, with all the delicate and interesting contrivances in connection with it for measuringand recording the behaviour of models in rolling or their resistance to motion through the water is a marvel of philosophical arrangement and practical skill. Mr. Froude's published papers include but a small portion, we believe, of his work. It would be a worthy tribute to his memory, and a great boon to science and to the shipping interests of the country if the result of his researches could be published in a complete form, and thus made readily accessible.

Mr. Froude had not much encouragement during the early days of his investigations upon these subjects. The first to appreciate their value were the late Prof. Rankine and Mr. Crossland, one of the constructors of the Navy. Mr. Crossland was one of the first to see that Mr. Froude, in his first paper on the Rolling of Ships, read before the Institution of Naval Architects in $186 \mathrm{I}$, had indicated the true laws of rolling motion, and in the following year he contributed an original paper upon the same subject. Mr. Reed was the first to apply the principles enunciated by Mr. Froude to the construction of ships; and did so with great ability and success. Canon Moseley, Dr. Woolley, and others did not see, however, for a considerable time, that Mr. Froude had made a great stride in advance of previous knowledge, and had really discovered the means that had long been wanted of arriving at a due comprehension of the dynamical laws which govern a ship's behaviour at sea. Mr. Froude's lucid and painstaking explanation of his theory and replies to the objection of Dr. Woolley and others produced in due time their full effect, and in the course of a very few years all who were capable of understanding the arguments upon which the theory was based were thoroughly convinced that Mr. Froude's method and its results were sound, and were such as could alone lead to improvement in this branch of science.

Mr. Froude's scientific reputation and the value of his work now rest upon a solid foundation. His discoveries have revolutionised whole theories of hydrodynamics, and have stood the test of practical application. He has received various honorary distinctions, such as the degree of LL.D. from the University of Glasgow, and the Royal Medal of the Royal Society; but his greatest distinction, and that with which his name will always be associated, is that, in an age when science is fashionable and many of its professors look more to the show than the substance, $\mathrm{Mr}$. Froude devoted his energies to a long and unwearied search after truth in a department of science that few knew anything about, and that could have no interest for the many, and he looked only to success for his reward. Happily, in this sense he was bountifully rewarded, and has left, both in the subject-matter of his researches and the example he set in pursuing them, a legacy to those who follow after which should stimulate them to work with all their might, with the one object of endeavouring also to attain unto truth and to be worthy of being admitted within the veil of the temple of nature.

\section{KARL $K O C H$}

$\mathrm{T}$ IERE are very few even among professed botanists, who avail themselves to any thing like the extent they might do of the teachings of a garden. And yet for the study of the life-history of plants and for the due estimation of their precise degree of relationship one to the other a garden offers in some ways-in many ways-unrivalled opportunities.

Karl Koch; whose death we lately recorded, was one of the few who had a right appreciation of the resources of a garden and who knew how to turn them to account. His tall, attenuated form and keen eye were to be observed at most of the International Botanical and Horticultural Congresses which have been held in various continental cities and in London in 1866 . Everywhere, by horticulturists as by botanists, his claims to high rank among his fellows and his title to respect and even affection for his personal qualities were acknowledged, so that it became a pain to those who saw him recently to notice his gradually failing powers and to see how the old spirit was curbed and checked by impaired physical health.

Karl Koch was born in Weimar in June, 1809. In that little capital he came in contact, as a youth, with Goethe, and it was partly owing to his influence and advice that Koch made his visits to the Caucasus and various parts of Asia Minor. Shortly after he had completed his studies in medicine and natural history at Jena and at Wiirzburg he set out on his travels, his special objects being the investigation of the vegetation and an inquiry into the original sources of our cultivated fruittrees. After two years' research he suffered so severely from the effects of sunstroke on Mount Ararat that he was obliged to return to Jena, but in 1843 he set out a second time for the East. Of his first journey an account was published in 1842 , under the title of "Travels through Russia," of his second, in I845, under that of "Wanderings in the East." A general account of his travels may be found in the Linnae for 1848 , in which publication also may be found catalogues and descriptive lists of the plants collected by him, together with remarks on the geographical distribution of plants in the Caucasus, \&c. On his return from this second expedition he became assistant-director of the Botanic Garden at Berlin, secretary of the Prussian Horticultural Society, and, a few years later, Professor of Botany in the University.

His position at Berlin gave him exceptional facilities for studying cultivated plants, and, accordingly, much of his botanical work consisted of monographs of Arads, Bromeliads, Agaves, and other plants, necessarily imperfectly preserved in herbaria. Many such monographs are scattered through the Wochenschrift of the Berlin Horticultural Society, and which was for many years edited by him. As a pomologist also he held no mean position, but the most interesting and valuable part of his labours, so far as this branch is concerned, are those relating to the origin of cultivated fruit trees, a subject intimately connected with the history and migrations of our own race.

His magrum opus, however, is his "Dendrology"-a scientific description of the trees and shrubs cultivated in the forests and gardens of central Europe, a work for which his travels bad well prepared him. For the purpose of compiling this volume Koch visited almost every country in Europe. All the great nurseries of the Continent and of our country were also inspected by him with the object of study or of securing specimens.

Despite small defects of method Koch's descriptions are excellent and characteristic, so much so, that it is a great pity that his work has not been translated into English. The technical details of his subject are enlivened by short biographical notices of the botanists and horticulturists whose names are the most prominently associated with the department of botany, of which his work treats. The reader of these interesting notes to an otherwise necessarily dry technical book will have no difficulty in understanding the estimation in which Koch's popular lectures on trees and on fruit trees in particular were held by the Berlin public.

In private life Koch was beloved for his uprightness, loyalty, and warm-hearted devotion to his friends. 